\title{
The differential expression of SPARC in esophageal squamous cell carcinoma
}

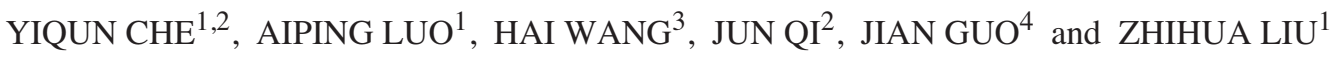 \\ ${ }^{1}$ National Laboratory of Molecular Oncology, ${ }^{2}$ Department of Clinical Laboratory, Cancer Institute and Hospital, \\ Chinese Academy of Medical Sciences and Peking Union Medical College, Beijing; ${ }^{3}$ Department of Clinical Laboratory, \\ China-Japan Union Hospital of Jilin University, Jilin; ${ }^{4}$ National Center for Clinical Laboratory, Beijing, P.R. China
}

Received November 4, 2005; Accepted December 23, 2005

\begin{abstract}
Secreted protein, acidic and rich in cysteine (SPARC) is a matricellular protein that modulates cell adhesion and growth. The aim of this study was to assess the prevalence of SPARC mRNA and protein expression in esophageal squamous cell carcinoma (ESCC) and to investigate the role of SPARC in proliferation and metastasis of ESCC. The differential expression of SPARC between esophageal squamous cell carcinoma and its corresponding normal esophageal mucosa was analyzed by semi-quantitative reverse transcription-polymerase chain reaction (RT-PCR), immunohistochemistry, as well as Western blotting. The expression of SPARC in ESCC was significantly higher than that in the corresponding normal esophageal mucosa as shown by semiquantitative RT-PCR, immunohistochemistry and Western blotting. Meanwhile, SPARC protein was also significantly up-regulated in ESCC compared with the corresponding normal esophageal mucosa. SPARC protein was located in the cytoplasm and nuclei of ESCC cells. The results of Western blotting showed that out of 18 paired samples, SPARC was up-regulated in 13 cases, no significant differences were found for the other 5 cases. These findings revealed that SPARC was up-regulated in ESCC and was closely associated with ESCC metastasis. This study provides new insights into nuclei location of SPARC.
\end{abstract}

Correspondence to: Professor Zhihua Liu, National Laboratory of Molecular Oncology, Cancer Institute, Chinese Academy of Medical Sciences and Peking Union Medical College, Beijing 100021, P.R. China

E-mail: liuzh@pubem.cicams.ac.cn

Abbreviations: SPARC, secreted protein, acidic and rich in cysteine; ESCC, esophageal squamous cell carcinoma; NSCLC, non-small cell lung cancer; ECM, extracellular matrix; RT-PCR, reverse transcription-polymerase chain reaction; FN, fibronectin; MMP-2, matrix metalloproteinase- 2

Key words: secreted protein, acidic and rich in cysteine, esophageal squamous cell carcinoma, gene expression

\section{Introduction}

Esophageal squamous cell carcinoma (ESCC) is the predominant histological subtype of esophageal cancer and is characterized by a high mortality rate and regional variation in incidence in China. As ESCC is usually diagnosed at a relatively late stage, treatment options are limited and the 5-year survival rate remains low.

Our previous work as well as the work from other groups showed obvious up-regulation of SPARC in human esophageal squamous cell carcinoma using cDNA microarray and other technologies. Our cDNA microarray results demonstrated a 3.78-fold increase in SPARC mRNA expression in human ESCC tissues (1). SPARC, also termed osteonectin or BM40, is a secreted glycoprotein that interacts with extracellular matrix (ECM) proteins to promote adhesion of cells from the matrix, thereby inducing a biological state conductive to cell migration. SPARC is also thought to play an important role in tissue remodeling, angiogenesis, embryonic development and tumorigenesis. SPARC was reported to be overexpressed in a variety of human malignancies, including glioma (2), melanoma (3), thyroid (4), stomach (5), bladder (6), breast (7), colon and rectum (8), prostate (9), hepatoma (10), kidney (11), and esophagus (12). However, SPARC was repressed in malignancies such as pancreas $(13)$, ovary $(14)$ and NSCLC $(15,16)$. Although overexpression of SPARC was observed in ESCC by two different groups, no details in mRNA level and the localization in the cells or tissues have been reported $(12,17)$. The aim of this study was to examine the expression and the localization of SPARC in ESCC and further demonstrate the relationship between the levels of SPARC and the clinical outcome.

SPARC is a multifunctional matricellular glycoprotein. In vitro, SPARC has antiangiogenic properties, including the ability to inhibit the proliferation and migration of endothelial cells stimulated by bFGF and VEGF. Previously, it was demonstrated that platelet-derived SPARC also inhibits angiogenesis and impairs the growth of neuroblastoma tumors in vivo. SPARC may regulate tumor growth by inhibiting angiogenesis, inducing tumor cell apoptosis and mediating changes in the deposition and organization of the tumor microenvironment (18). Croix et al (19), showed that SPARC is expressed in the tumor endothelium. SPARC and 
Table I. Clinical features of the ESCC cases and the quantity for each test.

\begin{tabular}{lrcc}
\hline Tissue diagnosis & RT-PCR & IHC & Western blot \\
\hline Lymph node metastasis & & & \\
Absent & 13 & 21 & 12 \\
Present & 11 & 15 & 6 \\
Differentiation & & & \\
Well & 7 & 12 & 9 \\
Moderate & 12 & 17 & 6 \\
Poor & 5 & 7 & 3 \\
\hline
\end{tabular}

other extracellular matrix molecules, thrombospondins-1 and -2 , fibronectin, nidogens 1 and 2, and collagen types VIII, $\mathrm{XV}$, and XVIII, are also differentially expressed by endothelium, varying with the endothelium type and/or pathophysiological state (20). SPARC expression does not significantly affect fibronectin-induced cell-spreading, but enhances fibronectin-induced stress fiber formation, and cell-mediated partial unfolding of fibronectin molecules, an essential process in fibronectin matrix assembly (21). SPARC was found to be independent of thrombospondin-1 expression (22). The motif of SPARC responsible for anti-spreading activity was dependent on the coordination of $\mathrm{Ca}^{2+}$ by a Glu residue at the $\mathrm{Z}$ position of EF-hand 2 and provide insights into how adhesive forces are balanced within the extracellular matrix of urothelial cells (23), matrix metalloproteinase-2 (MMP-2) and SPARC, the two major factors may be influenced in the ECM remodeling occurring with tumor invasion (24). These data further confirm the function of SPARC in extracellular matrix organization and identify a novel mechanism by which SPARC regulates extracellular matrix assembly. Although further study on SPARC in ESCC is necessary, these results will help us better understand the process of esophageal tumorigenesis and provide additional markers for the diagnosis and treatment of this disease.

\section{Materials and methods}

Patients and sample collection. Seventy-eight esophageal squamous cell carcinoma and paired normal mucosa specimens were obtained from patients who underwent surgery at Cancer Hospital, Chinese Academy of Medical Sciences and Peking Union Medical College and The First Affiliate Hospital of Anhui Medical College, China. We selected patients who had not been treated with radiotherapy or chemotherapy before surgery. The patients included 51 males and 27 females. Twenty-eight tumors were well differentiated, 35 were moderately differentiated, and 15 were poorly differentiated squamous cell carcinoma. The cases were classified into two groups: a non-metastatic group $(n=46,13$ for RT-PCR, 21 for IHC, 12 for Western blot) and a metastatic group $(n=32$, 11 for RT-PCR, 15 for IHC, 6 for Western blot) (Table I). Specimens were obtained from the tumor edge, avoiding the necrotic center, immediately after resection. Corresponding normal mucosa specimens at least $5 \mathrm{~cm}$ distant from the tumor edge were also obtained by sharply dissecting the mucosa from the muscularis propria. Fresh samples were immediately frozen into liquid nitrogen and stored at $-80^{\circ} \mathrm{C}$ until processing. The samples used for immunohistochemistry analysis were fixed in $4 \%$ polyformaldehyde and completely embedded in paraffin.

Cell lines. Human EC9706 esophageal squamous cell carcinoma (ESCC) cell line was established and maintained in our laboratory (25), the human esophageal squamous cell carcinoma (ESCC) cell lines KYSE30, KYSE150, KYSE410, KYSE450, and KYSE510 (26) were generous gifts from Dr Y. Shimada (First Department of Surgery, Faculty of Medicine, Kyoto University, Japan). All the cell lines were grown in RPMI-1640 medium supplemented with $10 \%$ FBS, $100 \mu \mathrm{g} / \mathrm{ml}$ streptomycin and $100 \mu \mathrm{g} / \mathrm{ml}$ penicillin $(\mathrm{pH} 7.2-7.4)$ in a humidified incubator containing $5 \% \mathrm{CO}_{2}$ at $37^{\circ} \mathrm{C}$.

$R T-P C R$. Total RNA was extracted using mRNA purification kit (Amersham Pharmacia, Inc., Piscataway, NJ, USA) from both cancerous and normal esophageal tissues. Total RNA (5 $\mu \mathrm{g}$ ) was converted to cDNA using SuperScript II reverse transcriptase (Invitrogen, Carlsbad, CA, USA). Briefly, total RNA was denatured at $65^{\circ} \mathrm{C}$ for $5 \mathrm{~min}$ in the presence of $0.5 \mu \mathrm{g}$ oligo dT and $1 \mathrm{mM}$ dNTPs. After chilling on ice for at least $1 \mathrm{~min}, \mathrm{RT}$ was allowed to proceed at $25^{\circ} \mathrm{C}$ for $5 \mathrm{~min}$ in the presence of $1 \mathrm{X}$ first-strand buffer, $5 \mathrm{mM}$ DTT and 40 units of RNase inhibitor. The reaction was then allowed to proceed at $50^{\circ} \mathrm{C}$ for another $60 \mathrm{~min}$. The reaction was terminated by heat inactivation at $70^{\circ} \mathrm{C}$ for $10 \mathrm{~min}$. RT-PCR was performed in a $25 \mu 1$ reaction mixture containing $50 \mathrm{mM}$ forward and reverse primers and $1 \mu \mathrm{l}$ cDNA. The reaction was performed with preliminary denaturation for $5 \mathrm{~min}$ at $94^{\circ} \mathrm{C}$ to activate Taq DNA polymerase, followed by 27 cycles of denaturation at $94^{\circ} \mathrm{C}$ for $30 \mathrm{sec}$, and extension at $58^{\circ} \mathrm{C}$ for $30 \mathrm{sec}$. Primers (Bio-Asia, Shanghai, China) were synthesized for the following sequences: forward 5'-TTGCCTGAGGCTGTAACTGA-3'; reverse 5'-GGGAGGGTGAAGAAAAGGAG-3'. The relative expression of genes was determined using RT-PCR with $B$-actin as an internal control.

Immunohistochemistry of SPARC. Paraffin sections from ESCC patients were treated by incubation with mouse monoclonal SPARC antibody (Wolwo Biotech Co., Shanghai, China) overnight at $4^{\circ} \mathrm{C}$ in a humid chamber, at the dilution of $1: 100$. For negative controls, the primary antibody was replaced by non-immune serum. Immunostaining was done by the avidinbiotin-peroxidase method. After immunostaining, the sections were imaged at magnification $\mathrm{x} 200$ by two pathologists who were blind to the clinical characteristics; three high-power fields were examined for each section. Cytoplasmic or nucleus patches of brown color were scored as SPARC positive. Comparisons were made between the intensity of the staining of the carcinoma cells and normal superficial epithelium on the same slide. The negative group consisted of cancer cells with no detectable (-) or only trace staining of SPARC immunoreactivity $( \pm)$. The positive group consisted of cancer cells with low $(1+)$, moderate $(2+)$ or high levels $(3+)$ of SPARC immunoreactivity. 


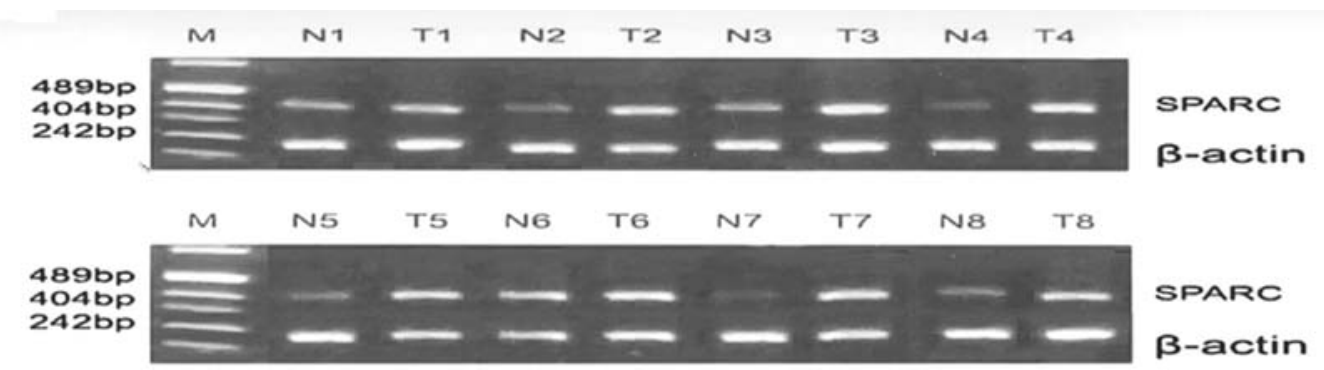

Figure 1. RT-PCR analysis showed the up-regulation of SPARC in ESCC paired tissues, B-actin served as an internal control. M, DNA marker; N, normal esophageal epithelium; T, esophageal squamous cell carcinoma.

Table II. Association between SPARC gene expression and pathological parameters by RT-PCR.

\begin{tabular}{lcccc}
\hline Tissue & $\mathrm{T} / \mathrm{N}$ & $\mathrm{T} / \mathrm{N}=$ & $\mathrm{T} / \mathrm{N}$ & Correlation \\
diagnosis & $>3$ & $1-3$ & $<1$ & $\mathrm{R}(\mathrm{P})$ \\
\hline
\end{tabular}

\section{Lymph node}

metastasis

$-0.470(0.021)$

$\begin{array}{lrrr}\text { Absent } & 8 & 4 & 1 \\ \text { Present } & 11 & 0 & 0\end{array}$

Differentiation

$\begin{array}{lrrr}\text { Well } & 5 & 1 & 1 \\ \text { Moderate } & 10 & 2 & 0 \\ \text { Poor } & 4 & 1 & 0\end{array}$

T, ESCC tissue specimen; $\mathrm{N}$, normal mucosa; $\mathrm{T} / \mathrm{N}>3$, the cases of significant differences; $\mathrm{T} / \mathrm{N}=1-3$ and $\mathrm{T} / \mathrm{N}<1$, the cases of no significant differences.

Western blot analysis. Total protein was extracted from 18 esophageal squamous cell carcinoma and the corresponding normal esophageal mucosa specimens by radio-immunoprotein assay (RIPA) buffer. The same aliquots $(30 \mu \mathrm{g})$ of total protein were applied to $12 \%$ acrylamide gradient gels and analyzed. The proteins were electroblotted onto a polyvinylidene difluoride membrane (Bio-Rad, Seattle, WA, USA) and SPARC was detected by using mouse monoclonal antibody against SPARC (Wolwo Biotech Co.) at a dilution of 1:1000.

Statistical analysis. The Chi-square test was used for betweengroup comparisons. The relationship between the results of two different examinations was analyzed by Spearman's correlation test. P-value $<0.05$ was considered to be statistically significant using a two-tailed test. Statistical analyses were carried out with SPSS data analysis program version 11.0 (SPSS Inc., Chicago, IL, USA).

\section{Results}

SPARC expression at $m R N A$ level in ESCC. RT-PCR analysis showed the differential expression of SPARC in 24 pairs of esophageal squamous cell carcinoma tissue samples and the matched normal tissue samples. The gene expression of
SPARC in ESCC by RT-PCR was higher than that in the corresponding normal esophageal mucosa. The expression of SPARC was increased in 19 pairs of ESCC samples (79\%), whereas no changes were observed in 5 cases of ESCC samples compared with their normal counterparts (Fig. 1). There is no relationship between SPARC expression and the histological differentiation of ESCC, however, the correlation does exist between the SPARC expression and the lymph node metastasis (Table II).

Overexpression of SPARC protein in ESCC tissues demonstrated by immunostaining. We examined the immunohistochemical staining patterns for SPARC in matched pairs of histologically normal esophageal mucosa and tumorous tissue specimens. The expression level of SPARC was significantly higher in tumorous tissues as compared with the normal epithelium. We observed up-regulated expression of SPARC in 30 out of 36 carcinomas ( $83 \%$ ), and no obvious changes in 6 cases. As shown in Fig. 2, the immunostaining was most marked in cancer cells, and weak staining was observed in the stroma cells or fibroblasts in ESCC tissues (B). Normal esophageal epithelium cells did not show staining (Fig. 2A), only a trace of immunoreactivity was distinguished in the adjacent non-cancerous mucosa (Fig. 2A). Among the 36 patients studied by immunohistochemistry, the intensity of immunostaining in tumor tissue was determined as negative (-) in $6(16 \%), 1+$ in $6(17 \%), 2+$ in $19(53 \%)$, and $3+$ in 5 patients (14\%). Immunostaining in normal esophageal epithelium cells was absent in 35 cases and \pm in 1 case. The SPARC expression levels in tumor tissue, as determined by immunohistochemistry, was comparable to RT-PCR. We then performed statistical analysis with respect to the correlation between the protein expression and histopathologic parameters. The association between SPARC expression and histopathologic differentiation was not statistically significant. However, higher expression of SPARC was significantly associated with lymph node metastasis $(\mathrm{P}<0.001)$ (Table III). The current finding are contrary to previous studies that SPARC immunolocated in the cytoplasm, whereas no reaction in the nuclei. The strong expression of SPARC was noted in the cytoplasm and nuclei of the tumor nest. SPARC is located only in cytoplasma in most cases (Fig. 2D), but the expression of 4 cases is in the nuclei and cytoplasma (Fig. 2C). In addition, SPARC is usually expressed only in carcinoma cells, not in adjacent fibroblasts in the center section of carcinoma tissue specimens, whereras its 
A

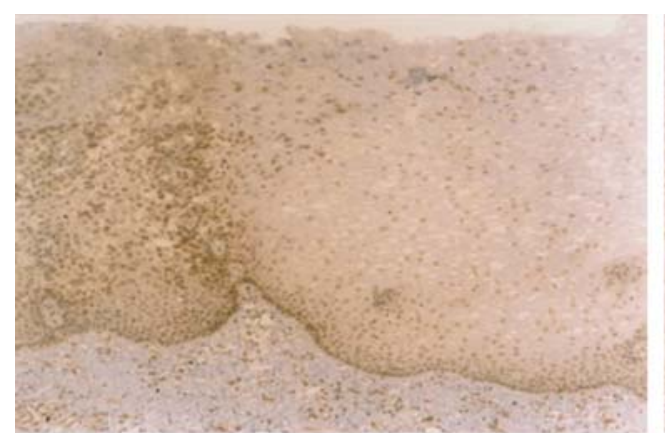

C

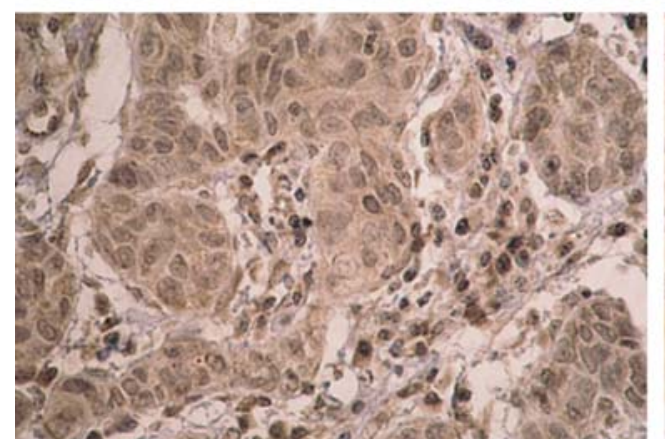

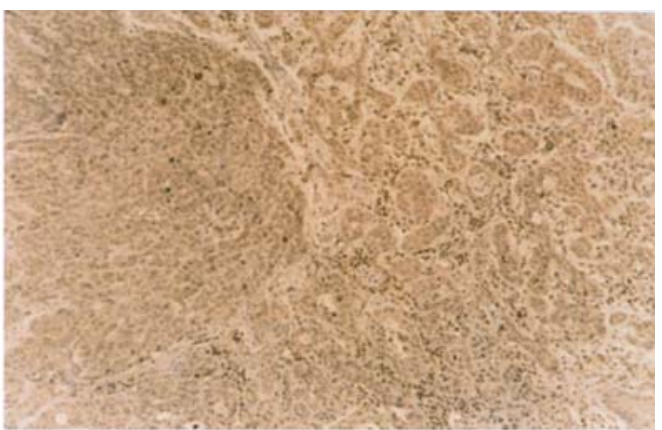

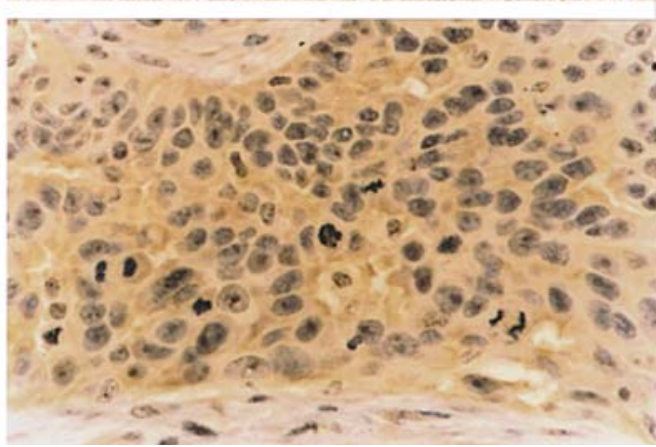

Figure 2. Immunohistochemical expression of SPARC protein in normal and ESCC tissues. (A) Trace immunostaining of SPARC in normal esophageal mucosa (original magnification, x100). (B) Strong SPARC staining in ESCC tissues (original magnification, x100). (C) Strong expression of SPARC in some cases is in nuclei and cytoplasma (original magnification, $\mathrm{x} 400$ ). (D) SPARC is located only in cytoplasma in most cases (original magnification, $\mathrm{x} 400$ ).

Table III. Association between SPARC expression and pathological parameters by IHC.

\begin{tabular}{llcccr}
\hline & \multicolumn{4}{c}{ SPARC positive cases (\%) } & Correlation R (P) \\
\cline { 2 - 5 } Tissue diagnosis & - & $1+$ & $2+$ & $3+$ & $0.591(0.000)$ \\
\hline $\begin{array}{l}\text { Lymph node metastasis } \\
\text { Absent }\end{array}$ & $6(28)$ & $5(24)$ & $10(48)$ & 0 & \\
Present & 0 & $1(7)$ & $9(60)$ & $5(33)$ & $0.099(0.565)$ \\
$\begin{array}{l}\text { Differentiation } \\
\text { Well }\end{array}$ & $2(17)$ & $2(17)$ & $7(58)$ & $1(8)$ & \\
Moderate & $3(18)$ & $3(18)$ & $9(53)$ & $2(11)$ & \\
Poor & $1(14)$ & $1(14)$ & $3(43)$ & $2(29)$ & \\
\hline
\end{tabular}

immunostaining was recognized in the stromal fibroblasts of invasive margin as well as in carcinoma cells. Trace immunostaining of SPARC was recognized in normal esophageal mucosa and submucosa samples including stromal cells.

SPARC protein was up-regulated in esophageal cancer tissues as detected by Western blot analysis. In the Western blot analysis, all carcinoma tissue specimens showed a band at 43 kilodalton $(\mathrm{kDa})$, which indicated SPARC expression, whereas normal tissue specimens showed weak reaction. The results of Western blotting revealed that the expression of SPARC protein was significantly up-regulated in ESCC compared with the corresponding normal esophageal mucosa in 13 cases $(\mathrm{P}<0.05)$, no significant differences in 5 cases (Fig. 3). Furthermore, SPARC was different in 7 esophageal squamous cell carcinoma cell lines (Fig. 3). KYSE150,
KYSE410 and KYSE510 showed higher expression, whereas KYSE510, KYSE450, COLO-680N and EC9706 showed low expression.

\section{Discussion}

The function of SPARC in the pathogenesis and behavior of human cancer is complex. SPARC increases the production of collagenase, stromelysin, gelatinase, fibronectin and laminin in fibroblasts (27). SPARC produced by melanoma cells modulates the antitumor activity of polymorphonuclear leukocytes (28). It functions as a counteradhesive protein, modifying cell shape through the dissociation of focal adhesion, and modulates cell-matrix interactions by binding to the extracellular matrix (ECM) (29). Increased synthesis of SPARC in submucosal fibroblasts has been reported in experimental 

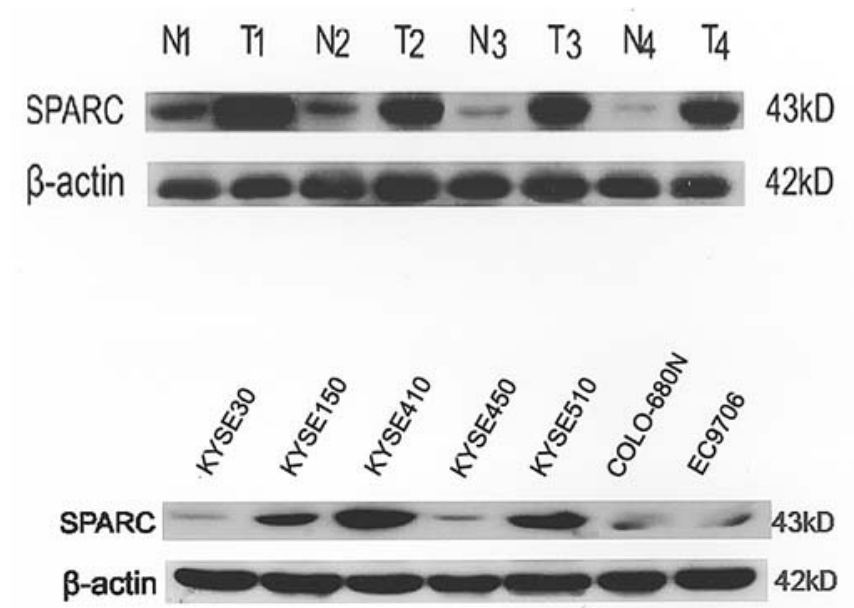

Figure 3. The expression pattern of SPARC in ESCC paired tissues and human esophageal cancer cell lines with Western blot analysis. SPARC protein was up-regulated in esophageal cancer tissue (T) compared to the matched almost normal tissues $(\mathrm{N})$. B-actin, internal control.

studies during the early steps of chemical carcinogenesis (30). Analysis of the SPARC transcript using RT-PCR has shown an up-regulation of SPARC mRNA by the fatty acid. Gamma linolenic acid (GLA) reduced cell-matrix adhesion in these cancer cells. It is concluded that GLA is a regulator of SPARC secretion and expression in cancer cells. GLA reduces the secretion of SPARC into surrounding environment, which may contribute to the reduction of cancer cell adhesion to the extracellular matrix and cell motility (31).

SPARC protein is suppressed in mature human tissues. Unlike fetal colon, normal adult colon does not express SPARC, whereas re-expression occurs in the stroma of colonic carcinomas (32). Similarly, SPARC is undetectable in normal and benign stomach tissues, whereas substantial amount of mRNA and protein are detected in the stroma of gastric carcinomas (33). In the present study, we used SPARC antibody, to investigate the expression patterns of SPARC in normal esophagus and ESCC. In normal esophagus, SPARC was confined to showing a rather weak expression, whereas a strong reactivity was noted in the esophageal squamous cell carcinoma. The findings were in accordance with other studies showing a lack of SPARC expression in normal liver, colon, stomach and kidneys. Although an extensive study on SPARC in normal tissues is not available, it seems that expression of this protein may persist in some mature human tissues, such as ovarian and prostate epithelium, chondrocytes, and placental trophoblasts $(9,14-16)$.

The major finding of the present study demonstrated a close association between SPARC overexpression and tumorigenesis of ESCC. A similar analysis of higher SPARC expression in tumor tissues has been reported in other malignancies $(6,8,11,12)$. Increased levels of SPARC were associated with lymph node metastasis in colorectal and esophageal cancers, liver metastasis in colorectal cancer and bone metastasis in prostate cancers $(8,9,12)$, but different from another report, where SPARC stained only the cytoplasma in ESCC tissues (12). Here we observed the expression of SPARC in cytoplasma as well as the nuclei.
The current finding contrasted to previous studies that SPARC located in the cytoplasm, whereas no reaction in the nuclei was observed $(12,34)$. The strong expression of SPARC was noted in the cytoplasm and nuclei of the tumor nest. Nuclear patterns of SPARC expression have also been reported in embryonic chick cells (35). In that study, the detection of SPARC in the interphase nuclei of embryonic chicken cells in vivo was reported. Immunocytochemical analysis of embryonic chicken cells in vitro likewise showed the presence of SPARC in the nucleus. Furthermore, elution of soluble proteins and DNA from these cells indicated that SPARC might be a component of the nuclear matrix. Subsequently cultured bovine aortic endothelial cells were examined, which initially appeared to express SPARC only in the cytoplasm. However, after elution of soluble proteins and chromatin, SPARC in the nuclear matrix of these cells was detected. A strong reactivity has been noted in the cytoplasm and nuclei of the bronchial cartilage and stromal fibroblasts (16). These observations provide new information on SPARC, generally recognized as a secreted glycoprotein that mediates interactions between cells and components of the extracellular matrix. The evidence presented in this study indicates that SPARC might subserve analogous functions in the nuclear matrix.

It has been demonstrated that SPARC is critical for tumor invasion, angiogenesis, and tumorigenesis. SPARC and matrix metalloproteinase-2 (MMP-2) occur through shared transcriptional regulation (AP-2, Sp1), SPARC induced transforming growth factor- $\beta 1$, which could transcriptionally activate MMP-2 and type I collagen (34). Briggs et al (7) showed that overexpression of the c-Jun proto-oncogene increased motility and invasion of $\mathrm{MCF}-7$ with transcriptional up-regulation of SPARC. It was also showed that SPARC abrogation using anti-sense oligonucleotides inhibited c-Junactivated MCF-7 motility and invasion, whereas the SPARC gene did not show increased motility and invasion in MCF-7. These finding indicated that SPARC is required but not sufficient for tumor invasion. It was concluded that higher expression of SPARC was significantly associated with lymph node metastasis $(\mathrm{P}<0.05)$.

In the current study, high SPARC expression was found to correlate significantly with lymph node metastasis. Similar result was reported in rectal carcinoma. SPARC expression was not associated with the histological differentiation. Originally, SPARC was found as a gene augmented in endothelial cells during angiogenesis. Years later, its expression was confirmed in tumor endothelium. It has been demonstrated that SPARC was related to angiogenesis-related gene expression such as thrombospondin-1, MMP-2 and tumor growth factor- $\beta$. In ESCC, angiogenic activity correlated with lymph node metastasis, which suggested that SPARC expression affects lymph node metastasis through angiogenesis.

SPARC is a powerful independent prognostic marker for short disease-free interval and poor overall survival of head and neck cancer patients (36). The up-regulation of SPARC mRNA expression is an early event in the development and progression of Barrett's esophagus and Barrett's-associated adenocarcinoma (37). Modulation of SPARC expression affects colorectal cancer sensitivity to radiation and chemotherapy. SPARC-based gene or protein therapy may 
ameliorate the emergence of resistant clones and eradicate existing refractory clones and offers a novel approach for cancer treatment (38). SPARC plays a crucial role in tumor development in breast cancer and as such has a significant bearing on patient prognosis and long-term survival (39).

Our study shows that SPARC might have potential diagnostic, prognostic and biological value in tumor assessment. However, the mechanism of its regulation remains unknown, further investigations are still needed to verify the involvement and the molecular mechanism of SPARC in ESCC development. Further investigations will be required to verify the involvement of SPARC in ESCC and to further elucidate the molecular mechanisms of ESCC development.

\section{Acknowledgements}

This study was co-supported by the China Key Program on Basic Research (2004CB518604), National Science Foundation of China (30425027), and the Chinese Hi-Tech R\&D program (2004AA231041).

\section{References}

1. Luo A, Kong J, Hu G, Liew CC, Xiong M, Wang X, Ji J, Wang T, Zhi H, Wu M and Liu Z: Discovery of $\mathrm{Ca}^{2+}$-relevent and differentiation-associated genes downregulated in esophageal squamous cell carcinoma using cDNA microarray. Oncogene 23: 1291-1299, 2004.

2. Menon PM, Gutierrez JA and Rempel SA: A study of SPARC and vitronectin localization and expression in pediatric and adult gliomas: high SPARC secretion correlates with decreased migration on vitronectin. Int J Oncol 17: 683-693, 2000.

3. Rumpler G, Becker B, Hafner C, McClelland M, Stolz W, Landthaler M, Schmitt R, Bosserhoff A and Vogt T: Identification of differentially expressed genes in models of melanoma progression by cDNA array analysis: SPARC, MIF and a novel cathepsin protease characterize aggressive phenotypes. Exp Dermatol 12: 761-771, 2003.

4. Takano T, Hasegawa Y, Matsuzuka F, Miyauchi A, Yoshida H, Higashiyama T, Kuma K and Amino N: Gene expression profiles in thyroid carcinomas. Br J Cancer 83: 1495-1502, 2000.

5. Wang CS, Lin KH, Chen SL, Chan YF and Hsueh S: Overexpression of SPARC gene in human gastric carcinoma and its clinic-pathologic significance. Br J Cancer 91: 1924-1930, 2004.

6. Yamanaka M, Kanda K, Li NC, Fukumori T, Oka N, Kanayama $\mathrm{HO}$ and Kagawa S: Analysis of the gene expression of SPARC and its prognostic value for bladder cancer. J Urol 166: 2495-2499, 2001.

7. Briggs J, Chamboredon S, Castellazzi M, Kerry JA and Bos TJ: Transcriptional upregulation of SPARC, in response to c-Jun overexpression, contributes to increased motility and invasion of MCF7 breast cancer cells. Oncogene 46: 7077-7091, 2002.

8. Van Beijnum JR, Moerkerk PT, Gerbers AJ, De Bruine AP, Arends J-W, Hoogenboom HR and Hufton SE: Target validation for genomics using peptide-specific phage antibodies: a study of five gene products overexpressed in colorectal cancer. Int J Cancer 101: 118-127, 2002.

9. Thomas R, True LD, Bassuk JA, Lange PH and Vessella RL: Differential expression of osteonectin/SPARC during human prostate cancer progression. Clin Cancer Res 6: 1140-1149, 2000.

10. Le Bail B, Faouzi S, Boussarie L, Guirouilh J, Blanc JF, Carles J, Bioulac Sage P, Balabaud C and Rosenbaum J: Osteonectin/ SPARC is overexpressed in human hepatocellular carcinoma. J Pathol 189: 46-52, 1999.

11. Sakai N, Baba M, Nagasima Y, Kato Y, Hirai K, Kondo K, Kobayashi K, Yoshida M, Kaneko S, Kishida T, Kawakami S, Hosaka M, Inayama $\mathrm{Y}$ and Yao M: SPARC expression in primary human renal cell carcinoma: upregulation of SPARC in sarcomatoid renal carcinoma. Hum Pathol 32: 1064-1070, 2001 .
12. Yamashita K, Upadhay S, Mimori K, Inoue H and Mori M: Clinical significance of secreted protein acidic and rich in cystein in esophageal carcinoma and its relation to carcinoma progression. Cancer 97: 2412-2419, 2003.

13. Sato N, Fukushima N, Maehara N, Matsubayashi H, Koopmann J, $\mathrm{Su} \mathrm{GH}$, Hruban $\mathrm{RH}$ and Goggins M: SPARC/osteonectin is a frequent target for aberrant methylation in pancreatic adenocarcinoma and a mediator of tumor-stromal interactions. Oncogene 22: 5021-5030, 2003.

14. Yiu GK, Chan WY, Ng SW, Chan PS, Cheung KK, Berkowitz RS and Mok SC: SPARC (secreted protein acidic and rich in cysteine) induces apoptosis in ovarian cancer cells. Am J Pathol 159: 609-622, 2001 .

15. Ito M, Ito G, Kondo M, Uchiyama M, Fukui T, Mori S, Yoshioka H, Ueda Y, Shimokata K and Sekido Y: Frequent inactivation of RASSF1A, BLU, and SEMA3B on 3p21.3 by promoter hypermethylation and allele loss in non-small cell lung cancer. Cancer Lett 225: 131-139, 2005.

16. Koukourakis MI, Giatromanolaki A, Brekken RA, Sivridis E, Gatter KC, Harris AL and Sage EH: Enhanced expression of SPARC/osteonectin in the tumor-associated stroma of non-small cell lung cancer is correlated with markers of hypoxia/acidity and with poor prognosis of patients. Cancer Res 63: 5376-5380, 2003.

17. Porte H, Triboulet JP and Kotelevets L: Overexpression of stromelysin-3, BM-40/SPARC, and MET genes in human esophageal carcinoma: implications for prognosis. Clin Cancer Res 4: 1375-1382, 1998.

18. Chlenski A, Liu S, Guerrero LJ, Yang Q, Tian Y, Salwen HR, Zage P and Cohn SL: SPARC expression is associated with impaired tumor growth, inhibited angiogenesis and changes in the extracellular matrix. Int J Cancer (In press).

19. Croix SB, Rago C, Velculescu V, Traverso G, Romans KE, Montgomery E, Lal A, Riggins GJ, Lengauer C, Vogelstein B and Kinzler KW: Genes expressed in human tumor endothelium. Science 289: 1197-1202, 2000

20. Hallmann R, Horn N, Selg M, Wendler O, Pausch F and Sorokin LM: Expression and function of laminins in the embryonic and mature vasculature. Physiol Rev 85: 979-1000, 2005.

21. Barker TH, Baneyx G, Cardo-Vila M, Workman GA, Weaver M, Menon PM, Dedhar S, Rempel SA, Arap W, Pasqualini R, Vogel V and Sage EH: SPARC regulates extracellular matrix organization through its modulation of integrin-linked kinase activity. J Biol Chem (In press).

22. Abeysinghe HR, Li LQ, Guckert NL, Reeder J and Wang N: THY-1 induction is associated with up-regulation of fibronectin and thrombospondin-1 in human ovarian cancer. Cancer Genet Cytogenet 161: 151-158, 2005.

23. Delostrinos CF, Hudson AE, Feng WC, Kosman J and Bassuk JA: The C-terminal $\mathrm{Ca}^{2+}$-binding domain of SPARC confers antispreading activity to human urothelial cells. J Cell Physiol (In press).

24. Gagliano N, Moscheni C, Torri C, Magnani I, Bertelli AA and Gioia M: Effect of resveratrol on matrix metalloproteinase-2 (MMP-2) and secreted protein acidic and rich in cysteine (SPARC) on human cultured glioblastoma cells. Biomed Pharmacother 59: 359-364, 2005.

25. Han Y, Wei F, Xu X, Cai Y, Chen B, Wang J, Xia S, Hu H, Huang X, Han Y, Wu M and Wang M: Establishment and comparative genomic hybridization analysis of human esophageal carcinomas cell line EC9706. Zhonghua Yi Xue Yi Chuan Xue Za Zhi 19: 455-457, 2002.

26. Shimada Y, Imamura M, Wagata T, Yamaguchi N and Tobe T: Characterization of 21 newly established esophageal cancer cell lines. Cancer 69: 277-284, 1992.

27. Kato Y, Lewalle JM, Baba Y, Tsukuda M, Sakai N, Baba M, Kobayashi K, Koshika S, Nagashima Y, Frankenne F, Noel A, Foidart JM and Hata RI: Induction of SPARC by VEGF in human vascular endothelial cells. Biochem Biophys Res Commun 287: 422-426, 2001.

28. Alvarez MJ, Prada F, Salvatierra E, Bravo AI, Lutzky VP, Carbone C, Pitossi FJ, Chuluyan HE and Podhajcer OL: Secreted protein acidic and rich in cysteine produced by human melanoma cells modulates polymorphonuclear leukocyte recruitment and antitumor cytotoxic capacity. Cancer Res 65: 5123-5132, 2005.

29. Bradshaw AD and Sage EH: SPARC, a matricellular protein that functions in cellular differentiation and tissue response to injury. J Clin Invest 107: 1049-1054, 2001. 
30. Maeng HY, Choi DK, Takeuchi M, Yamamoto M, Tsukamoto T, Tatematsu M, Ito T, Sakaki Y and Furihata C: Appearance of osteonectin expression fibroblastic cells in early rat stomach carcinogenesis and stomach tumors induced with N-methyl-N/nitro-N-nitrosoguanidine. Jpn J Cancer Res 93: 960-967, 2002.

31. Watkins G, Martin TA, Bryce R, Mansel RE and Jiang WG: Gamma-linolenic acid regulates the expression and secretion of SPARC in human cancer cells. Prostaglandins Leukot Essent Fatty Acids 72: 273-278, 2005.

32. Lussier C, Sodek J and Beaulieu JF: Expression of SPARC/ osteonectinn/BM40 in the human gut: predominance in the strroma of the remodeling distal intestine. J Cell Biochem 81: 463-476, 2001

33. Maeng HY, Song SB, Choi DK, Kim KE, Jeong HY, Sakaki Y and Furihata C: Osteonectin-expressing cells in human stomach cancer and their possible clinical significance. Cancer Lett 184: 117-121, 2002.

34. Huang H, Colella S, Kurrer M, Yonekawa Y, Kleihues P and Ohgahi H: Gene expression profiling of low-grade diffuse astrocytomas by cDNA arrays. Cancer Res 60: 6868-6874, 2000.

35. Gooden MD, Vernon RB, Bassuk JA and Sage EH: Cell cycledependent nuclear location of the matricellular protein SPARC: association with the nuclear matrix. J Cell Biochem 74: 152-167, 1999.
36. Kato Y, Nagashima Y, Baba Y, Kawano T, Furukawa M, Kubota A, Yanoma S, Imagawa-Ishiguro Y, Satake K, Taguchi T, Hata R, Mochimatsu I, Aoki I, Kameda Y, Inayama Y and Tsukuda M: Expression of SPARC in tongue carcinoma of stage II is associated with poor prognosis: an immunohistochemical study of 86 cases. Int J Mol Med 16: 263-268, 2005.

37. Mitas M, Almeida JS, Mikhitarian K, Gillanders WE, Lewin DN, Spyropoulos DD, Hoover L, Graham A, Glenn T, King P, Cole DJ, Hawes R, Reed CE and Hoffman BJ: Accurate discrimination of Barrett's esophagus and esophageal adenocarcinoma using a quantitative three-tiered algorithm and multimarker real-time reverse transcription-PCR. Clin Cancer Res 11: 2205-2214, 2005.

38. Tai IT, Dai M, Owen DA and Chen LB: Genome-wide expression analysis of therapy-resistant tumors reveals SPARC as a novel target for cancer therapy. J Clin Invest 115: 1492$1502,2005$.

39. Watkins G, Douglas-Jones A, Bryce R, Mansel RE and Jiang WG: Increased levels of SPARC (osteonectin) in human breast cancer tissues and its association with clinical outcomes. Prostaglandins Leukot Essent Fatty Acids 72: 267-272, 2005. 